\title{
Furuncular myiasis of the foot caused by the tumbu fly, Cordylobia anthropophaga: report in a medical student returning from a medical mission trip to Tanzania
}

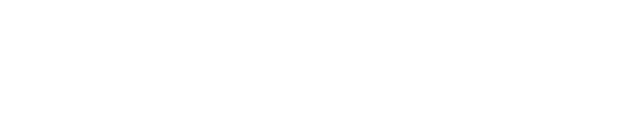

James R Palmieri ${ }^{1}$

Dwayne North'

Arben Santo ${ }^{2}$

'Department of Microbiology, Infectious and Emerging DiseasesEdward Via College of Osteopathic Medicine-Virginia Campus, Blacksburg, Virginia, USA; ${ }^{2}$ Department of Pathology-Edward Via College of Osteopathic Medicine-Virginia Campus, Blacksburg, Virginia, USA
Correspondence: James R Palmieri Department of Microbiology, Infectious and Emerging Diseases, Edward Via College of Osteopathic Medicine, 2260 Kraft Drive, Blacksburg, VA 24060, USA

Email jpalmieri@vcom.vt.edu

\begin{abstract}
Cutaneous myiasis in humans is a temporary parasitic infestation of the skin by fly larvae or maggots of a variety of Dipteran families. In the United States, autochthonous cases of myiasis are infrequently seen. Most cases of cutaneous myiasis are acquired when traveling to tropical areas of Africa, Central America or South America. This case report involves a 26-yearold male medical student who visited Tanzania on a medical mission trip. Three weeks following his return to the United States he developed a furuncular lesion on the side of the fifth digit on his right foot, which contained the larva of the tumbu fly, Cordylobia anthropophaga.
\end{abstract}

Keywords: Cordylobia anthropophaga, furuncular myiasis, phenylacetaldehyde, phenylacetic acid, Tanzania, tumbu fly

\section{Introduction}

Myiasis in humans is the infestation by fly larvae or maggots of a variety of Dipteran families. The infestation consists of larvae feeding on host tissue. Clinical presentations of myiasis in humans have been classified as cutaneous myiasis (furuncular and migratory), wound myiasis, and myiasis of body cavities. ${ }^{1-4}$ Diptera is a large order of insects that are commonly known as true flies. The taxonomic classification of the orders of Diptera which produce myiasis includes the superfamilies of Muscoidea (dung and house flies), Oestridae (botflies), Calliphoridae (blowflies), and Sarcophagidae (fleshflies). ${ }^{1,2,5}$ These families contain all species that are responsible for myiasis in humans. Cutaneous myiasis, the most frequent form, occurs after penetration by dipteran larvae into healthy skin. Subdivisions of cutaneous myiasis include furuncular myiasis in which a furuncle-like nodule develops with one or more maggots in it, and migratory myiasis in which the maggots migrate aimlessly through burrows in the skin and produce numerous furuncular lesions. Wound myiasis occurs when maggots infest open wounds such as neuropathic or vascular insufficiency ulcers, basal cell carcinoma, and psoriasis skin. ${ }^{2-5}$ Myiasis of body cavities is characterized by the invasion of body organs such as orbit, mouth, external ear, nasal cavity, nasopharynx, vulva, vagina, bladder, lung, or intestines by fly larvae. ${ }^{5}$

Most cases of myiasis in the United States are imported, having been acquired in Africa, Central America, or South America. When acquired in the United States, myiasis is often the result of accidental infestation by larvae of rabbit or by rodent bot flies of the genus Cuterebra. ${ }^{3}$ 
Cutaneous myiasis is often misdiagnosed in the United States because it is rarely seen in the clinical setting. Symptoms of cutaneous myiasis are not specific and are often confused with other conditions such as actinomycosis, staphylococcal boil, cellulitis, sebaceous cyst, leishmaniasis, tungiasis, mycosis, furunculosis, chronic breast abscess, furuncular breast lesions resulting from tuberculosis, fungating malignancies, and insect bite. ${ }^{2,6,7}$ Diabetic patients, especially elderly patients in a low-nutritional or immunocompromised state, are prone to opportunistic infection including myiasis. ${ }^{8}$ Noma (cancrum oris) is a rapidly progressive, polymicrobial, opportunistic infection of the face, mouth and cheeks that occurs during periods of compromised immune function and is characterized by gangrenous necrotizing lesions. Noma, immunosuppression resulting from steroid therapy, corticosteroid immunosuppressive therapy for psoriasis, malnutrition, HIV-infection and AIDS, prolonged hospitalization, diabetes, and extreme poverty all may produce lesions or wounds which may act as pre-existing factors of myiasis. ${ }^{9,10}$

\section{Case report}

During the summer of 2012, a 26-year-old male medical student visited Ntagatcha, Tanzania for a medical mission trip. Three weeks following his return to the United States, he noticed a scab developing on the side of the fifth digit on his right foot (Figure 1). He dismissed the scab as a simple corn or callus, which he thought was a result of his close fitting shoes and soccer cleats. One month later, he noticed that the scab became raised and sore with activity. One week later he noticed the scab looked greenish and decided to remove its top layer. Instead, an entire plug of

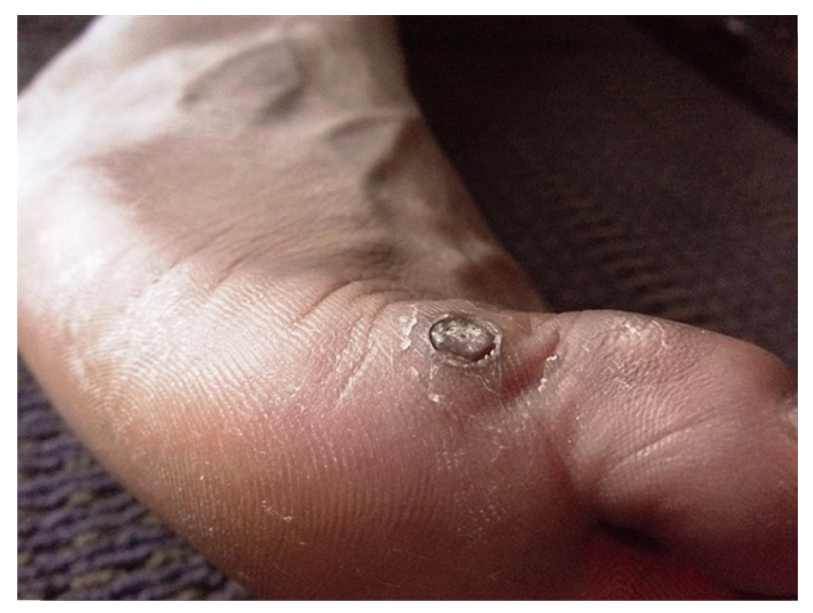

Figure I Circular ulcerous furuncular lesion of the lateral dorsum of the right foot, adjacent to the base of the fifth toe, containing a compressed prepupal larva of the tumbu fly, Cordylobia anthropophaga. dead flesh came neatly out of the side of his foot, leaving a well-circumscribed crater (Figure 2). There was neither bleeding nor pus discharge from the crater, but there was what seemed like pus at the bottom layer of the plug. On closer inspection of the plug, the student noticed that the pus-like layer was moving rhythmically, as if breathing. Suspecting a larva, he placed the plug in $70 \%$ alcohol to preserve it and two days later took it to Edward Via College of Osteopathic Medicine, Department of Microbiology Diagnostic Laboratory for evaluation.

The compressed larva was approximately $12 \mathrm{~mm}$ in length, yellow-brown, with two longitudinal stripes on the thorax and transverse black bands on the abdomen. The oral area contained a pair of toothed, spade-like hooks. There were fleshy processes extending posteriorly from the eighth abdominal segment. The posterior segment contained the characteristic spiracles, which lacked a chitinous rim (Figure 3). The size and morphology of the larva is consistent with those reported for the tumbu fly, Cordylobia anthropophaga.

\section{Discussion}

The African tumbu fly (also known as the mango fly and putzi fly) is responsible for the majority of furuncular lesions in Sub-Saharan, Central, and West Africa. ${ }^{1-3,6,11-13}$ Infestation in humans by larvae of the tumbu fly was first described in a patient from Senegal in $1862 .{ }^{1}$ Female tumbu flies normally oviposit between 100-300 eggs, usually in an aggregate mass, in sandy soil or sod contaminated with animal feces, urine, or garbage. ${ }^{1,14}$ The hatched larvae can remain viable in the soil for 9-15 days, until at which time they need to find a host for further development. ${ }^{15}$ The tumbu fly may deposit eggs on clothing that has been spread on the ground to dry, on improperly washed diapers placed in the shade to

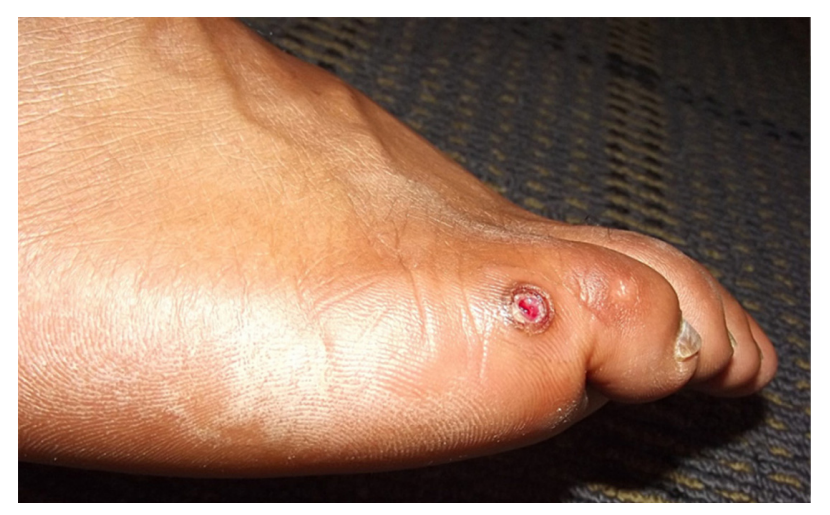

Figure 2 Circular ulcerous furuncular lesion of the lateral dorsum of the right foot, adjacent to the base of the fifth toe, 24 hours following the removal of a prepupal larva of the tumbu fly, Cordylobia anthropophaga. 


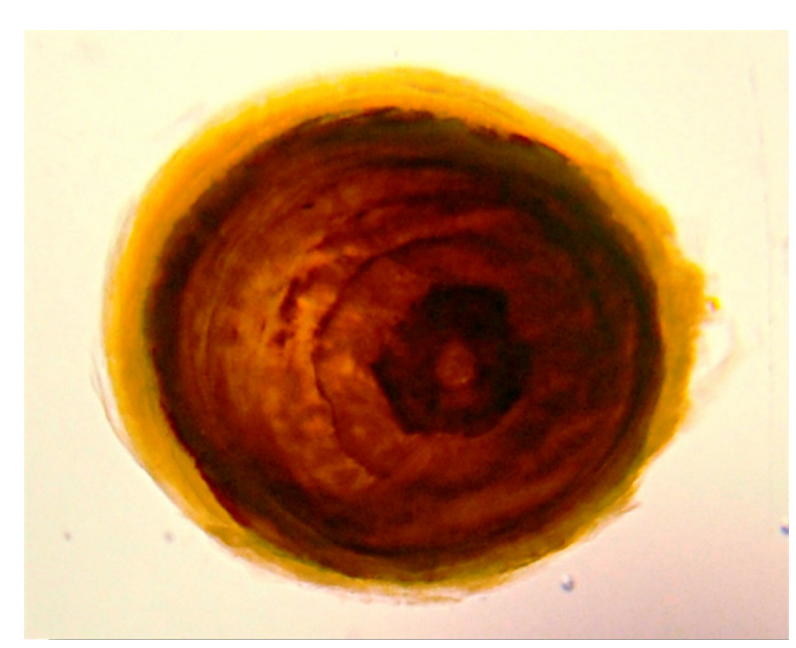

Figure 3 Posterior end of the prepupal larva of the tumbu fly, Cordylobia anthropophaga, showing characteristic respiratory spiracles.

dry, or on clothing soiled with urine or feces. ${ }^{1,3}$ Larvae hatch and when the clothing is subsequently worn, larvae may penetrate intact skin. ${ }^{3}$ Once the larvae penetrate the skin, their development may take 8-12 days to proceed through three stages of larval development prior to entering the prepupal stage. ${ }^{16}$ The prepupa then leaves the host, drops to the ground, buries itself, and pupates into an adult fly able to reproduce and begin the cycle all over again. ${ }^{1}$

Furuncular myiasis in humans presents as a small erythematous papule or nodule that grows into a large and tender boil-like lesion with a central pore that exudes serous or purulent fluid. ${ }^{5,7,17}$ In the central pore, the posterior segment of the larva bearing the respiratory spiracle may be protruding and visible. ${ }^{5}$ Pruritus, pain, and movement sensation are the most commonly reported symptoms. ${ }^{5,7,17}$

Furuncular myiasis is easily diagnosed solely on clinical observation, especially when there is a history of travel to endemic areas. Clinical laboratory examination results are usually normal. In cases of multiple infestations, peripheral eosinophilia and elevated immunoglobulin E levels may be found. Biopsies are not necessary for the diagnosis. ${ }^{5,17}$ Histopathological examination reveals the dipteran larva located in the dermis within a fibrous cystic sinus tract. The dermis contains an intense inflammatory infiltrate composed of lymphocytes and neutrophils. ${ }^{5}$

Most individuals request removal of the larvae at the time of diagnosis. There are many reports in the literature of methods for removal of the infesting fly larvae from the furuncle, since most individuals are reluctant to wait the required 8-12 weeks for the larvae to mature and exit on their own. ${ }^{14}$ Removal methods include application of lateral pressure, suffocation of the larvae by occlusion of the pore with medicinal liquid paraffin, mineral oil, petroleum jelly, pork fat, bacon, or by more invasive surgical incision if required to avoid rupture of the larvae and consequent granulomatous reaction. ${ }^{12,14,17}$ Secondary infection by pyogenic bacteria is uncommon in the furuncular skin lesions because of the bacteriostatic activity of the fly larva in skin. ${ }^{2}$ During larval life, the wound continually oozes serous fluid or pus, but bacteriostatic activity of phenylacetic acid and phenylacetaldehyde in the gut of the fly larva seems to prevent undesirable overgrowth of pyogenic bacteria. ${ }^{18,19}$

The first year medical student probably acquired the tumbu fly infestation on the base of his fifth toe when he contacted eggs directly on his skin from contaminated soil at the medical mission site or by contacting eggs which were oviposited on the cloth webbing of his sandals, which happened to cover the area where the furuncular lesion subsequently developed. The compressed appearance of the prepupal larva recovered from the student (Figure 3) reflects the compression on the developing larva by the subject's shoe.

\section{Conclusion}

Myiasis may be prevented by protecting laundry by ironing, drying in full sunlight off of the ground, or drying in a ventilated area, under mosquito netting or in an electric dryer if available. ${ }^{2,20}$ People in endemic areas should avoid wearing clothing that has been in contact with the ground. ${ }^{2,11}$ The use of insect repellent on the skin is not justified in preventing furuncular myiasis ${ }^{11}$ as suggested by the World Health Organization for the prevention of malaria. ${ }^{21}$ Use of an occlusive ointment or mechanical extraction is usually successful in treating furuncular myiasis with no long term consequences. ${ }^{3}$ The public health aspects of furuncular myiasis caused by Cordylobia anthropophaga involve the use of simple measures such as washing and thoroughly drying clothes, improving personal sanitation and hygiene, and using insecticides to eliminate the flies from living and work areas. ${ }^{2}$ With the increase in travel to areas where furuncular myiasis is endemic, it is important that returning travelers become familiarized with the clinical presentation and treatment of furuncular myiasis, especially if being treated by physicians in non-tropical countries. Ultimately, this may avoid a misdiagnosis, delay in diagnosis, or unnecessary treatment with antibiotics. ${ }^{1,6}$

\section{Disclosure}

The authors report no conflicts of interest in this work. 


\section{References}

1. Rice PL, Gleason N. Two cases of myiasis in the United States by the African tumbu fly, Cordylobia anthropophaga (Diptera, Calliphoridae). Am J Trop Med Hyg. 1972;21(2):62-65.

2. Musa HA, Allah EMW. Cutaneous myiasis caused by Cordylobia Anthropophaga: description of a case from Gazira State - Sudan. Sudanese J Pub Health. 2008;3(2):91-93.

3. Safdar N, Young DK, Andes D. Autochthonous furuncular myiasis in the United States: case report and literature review. Clin Infect Dis. 2003;36(7):e73-e80.

4. Biggar RJ, Morrow H, Morrow RH. Extensive myiasis from tumbu fly larvae in Ghana, West Africa. Clin Pediatr (Phila). 1980;19(3): 231-232.

5. Francesconi F, Lupi O. Myiasis. Clin Microbiol Rev. 2012;25(1): 79-105.

6. Adisa CA, Mbanaso A. Furuncular myiasis of the breast caused by the larvae of the tumbu fly (Cordylobia anthropophaga). BMC Surg. 2004; $4: 5$.

7. Mazigo HD, Bahemana E, Dyegura O, et al. Severe tungiasis in northwest Tanzania: a case series. J Pub Hlth Africa. 2011;2(2):87-89.

8. Verettas DA, Chatzipapas CN, Drosos GI, et al. Maggot infestation (myiasis) of external fixation pin sites in diabetic patients. Trans $R$ Soc Trop Med Hyg. 2008;102(9):950-952.

9. Aguiar AM, Enwonwu CO, Pires FR. Noma (cancrum oris) associated with oral myiasis in an adult. Oral Dis. 2003;9(3):158-159.

10. Dagci H, Zeyrek F, Gerzile YK, Sahin SB, Yagci S, Uner A. A case of myiasis in a patient with psoriasis from Turkey. Parasitol Int. 2008;57(2):239-241.

11. Dehecq E, Nzungu PN, Cailliez JC, et al. Cordylobia anthropophaga (Diptera: Calliphoridae) outside Africa: a case of furuncular myiasis in a child returning from Congo. J Med Entomol. 2005;42(2):187-192.
12. Curtis SJ, Edwards C, Athulathmuda C, Paul J. Case of the month: cutaneous myiasis in a returning traveller from the Algarve: first report of tumbu maggots, Cordylobia anthropophaga, acquired in Portugal. Emerg Med J. 2006;23(3):236-237.

13. Travel Health Unit, National Institutes for Communicable Diseases - National Health Laboratory Service. Furuncular myiasis due to Cordylobia anthropophaga: the tumbu fly. Communicable Diseases Communiqué. 2011;10(4):3.

14. Horen WP. Myiasis of the foot caused by Phaenicia sericata (Meigen). Calif Med. 1967;107(1):47-48.

15. Ockenhouse CF, Samlaska CP, Benson PM, et al. Cutaneous myiasis caused by the African tumbu fly (Cordylobia anthropophaga). Arch Dermatol. 1990;126(2):199-202.

16. Geary MJ, Hudson BJ, Russell RC, Hardy A. Exotic myiasis with Lund's fly (Cordylobia rodhalni). Med J Aust. 1999;171(11-12):654-655.

17. Boggild AK, Keystone JS, Kain KC. Furuncular myiasis: a simple and rapid method for extraction of intact Dermatobia hominis larvae. Clin Infest Dis. 2002;35(3):336-338.

18. MacNamara A, Durham S. Dermatobia hominis in the accident and emergency department: "I've got you under my skin." J Accid Emerg Med. 1997;14(3):179-180.

19. Erdmann GR. Antibacterial action of myiasis-causing flies. Parasitol Today. 1987;3(7):214-216.

20. Douma RA, ten Wolde M, van Thiel PP, van Vugt M. A patient with prickling boils. Neth J Med. 2009;67(1):37-38.

21. World Health Organization World Malaria report 2012 [webpage on the Internet]. World Health Organization. Available from: http://www. who.int/malaria/publications/world_malaria_report_2012/en/index. html. Accessed June 6, 2013.
International Medical Case Reports Journal

\section{Publish your work in this journal}

The International Medical Case Reports Journal is an international, peer-reviewed open-access journal publishing original case reports from all medical specialties. Previously unpublished medical posters are also accepted relating to any area of clinical or preclinical science. Submissions should not normally exceed 2,000 words or

\section{Dovepress}

4 published pages including figures, diagrams and references. The manuscript management system is completely online and includes a very quick and fair peer-review system, which is all easy to use. Visit $\mathrm{http}: / /$ www.dovepress.com/testimonials.php to read real quotes from published authors. 